Article

\title{
Optimal Timing of Greenhouse Gas Emissions Abatement in Europe
}

\author{
Chryso Sotiriou and Theodoros Zachariadis *(1) \\ Department of Environmental Science and Technology, Cyprus University of Technology, 3603 Limassol, Cyprus; \\ cx.sotiriou@edu.cut.ac.cy \\ * Correspondence: t.zachariadis@cut.ac.cy; Tel.: +357-25-002304
}

Received: 23 April 2019; Accepted: 14 May 2019; Published: 16 May 2019

\begin{abstract}
Decarbonization by the mid-21st century requires strong commitment to greenhouse emission abatement measures, but national emission reduction pledges are made for the medium term. Achieving medium term targets without taking into account the long term can lead to a lock-in effect, binding countries in pathways that cannot lead to strong decarbonization. This paper sheds light in this issue by combining a theoretical approach with real-world engineering and cost data. We develop a constrained optimization model to examine least-cost greenhouse gas emission abatement pathways, taking into account (a) emission reduction objectives for two years: 2030 and 2050; and (b) the potential speed of implementation of each measure, which expresses technical and behavioural inertia in the deployment of a measure. We focus on European countries and economic sectors that are not subject to the EU Emissions Trading System. We derive relationships between 2030 abatement targets of varying ambition and the possibility for a country to achieve a strong 2050 target. We find that more ambitious EU-wide targets have to be set by 2030 so that Europe delivers deep decarbonization by 2050. Moreover, if air pollution costs are taken into account, strong decarbonization by 2050 has lower social costs than less ambitious policies.
\end{abstract}

Keywords: climate policy; decarbonization; emissions trading system; energy policy

\section{Introduction}

Many governments around the world are committing themselves to increasingly stringent energyand climate-related targets for the medium and long term in order to bring their policies in line with the Paris Agreement on Climate Change, which was adopted in 2015 [1]. Such commitments are usually expressed as a pledge to curb greenhouse gas (GHG) emissions by a certain percentage rate up to 2030, 2040 or 2050, compared to a reference year of the past. Following the declarations of some European countries, in late 2018 the European Commission (the executive body of the European Union) declared that it would aim to achieve 'climate neutrality' by 2050, i.e., achieve zero net GHG emissions into the atmosphere [2].

In order to fulfil such pledges, policymakers have to design proper and cost-effective decarbonization strategies. This involves deciding an appropriate mix of GHG abatement policies and measures that can be implemented so as to meet the emission reduction objective in the target year, at the least cost to society. Such analyses are often carried out with the aid of Integrated Assessment Models or national forecast models, which lead to a cost-optimal set of policies. Sometimes the optimization procedure concludes with the development of a marginal emissions abatement cost curve (MACC), which ranks all abatement measures according to their cost per tonne of GHG abated and can serve as a guide to policymakers for prioritizing specific measures [3].

Being simplified representations of socio-technical systems, all modelling approaches are subject to uncertainties and weaknesses, which become more pronounced under a complex political reality. For example, EU Member States have committed to a specific emissions reduction target for the year 
2030: $40 \%$ lower GHG emissions compared to 1990. At the same time there are political declarations for 2050 as well: EU leaders have expressed their intention to achieve $80-95 \%$ lower emissions by the year 2050, and the European Commission has stated its 2050 climate-neutrality target mentioned above. This means that European policymakers need to find cost-optimal decarbonization policies which can fulfil the pledges for both 2030 and 2050. Even ignoring the uncertainties in the evolution of costs and abatement potential of specific technologies up to 2050, such an optimization is not straightforward because investments made up to 2030 with a long lifetime will affect the emissions of 2050 as well. As the 2050 decarbonization target is much more ambitious than the one for 2030, meeting the 2030 objective without keeping in mind the longer term may make it impossible-or very costly-to fulfil the 2050 commitment. This is often called a 'lock-in' effect-prioritizing abatement options which are cheaper and faster to implement but do not have sufficient potential to meet ambitious abatement targets $[4,5]$.

Similar challenges apply to any country of the world. It has been argued that the long-term GHG development strategies required by the Paris agreement on climate change have to be formulated in such a way that enables reconciling the long-term and global nature of the climate objective with the medium-term horizon and national scale of the Nationally Determined Contributions provided by each country [6].

In this paper we attempt to shed light in this issue by combining a theoretical approach with empirical work in order to contribute to the design of policies for simultaneously achieving decarbonization targets in the medium and the long term. We develop a multi-objective constrained optimization model to examine least-cost GHG emission abatement pathways, taking into account (a) emission reduction objectives for two years: 2030 and 2050; and (b) the potential speed of implementation of each measure, which expresses technical and behavioural inertia in the deployment of a measure.

The challenge of meeting emission abatement targets in two different periods has been identified in the past. Vogt-Schilb and Hallegatte [3] developed an optimization model for two theoretical emission reduction measures which have different costs and different potential to meet 2030 and 2050 targets, and have introduced a variable to capture the speed of implementation of each measure. They applied this approach in a real-world setting, by developing an improved MACC for Brazil [7]. We expand their approach by (a) adapting it to the EU policy setting, as explained below, and (b) making the implementation speed of each abatement measure variable over time and dependent on the cumulative amount of abatement that has already been deployed up to a given year.

The EU's approach is to treat decarbonization targets separately for heavy industry and the rest of the economy. Heavy industrial installations (including power generation) are subject to the EU Emissions Trading System (ETS), a cap-and-trade system in which most emission allowances will be auctioned from 2021 onwards. All other sectors of the economy (light industry, transport, agriculture, residential and commercial sectors) are subject to an aggregate emission reduction objective for 2030, which is different for each country. Our optimization model focuses on all these non-ETS sectors, which comprise a diverse mix of economic activities and GHG abatement options. Achieving non-ETS decarbonization targets is considered very challenging for most EU countries, probably more so than the targets for the heavy industry subject to the ETS [8].

A further contribution of our paper is that it takes into account additional benefits of GHG emission abatement. We express these benefits in monetary terms, i.e., the avoided damage costs because of lower emissions of GHG and major air pollutants nitrogen oxide (NOx), particulate matter (PM) and sulphur dioxide $\left(\mathrm{SO}_{2}\right)$. Although air quality improvement is recognized as an important side-benefit of decarbonization strategies, it has not been addressed explicitly in climate policy models up to now.

The starting point of this modelling work was the development of a static MACC for Cyprus-an EU country that is faced with a demanding non-ETS decarbonization target [9]. The initial technical and economic data were collected in the frame of that work. However, this paper distances itself from the specific case study of Cyprus; although it uses the same data as a starting point, the assumptions to be presented in the following section about the future evolution of costs, abatement potential and 
speed of implementation are more generic, as the optimization model is intended to be relevant for any country seeking cost-optimal decarbonization pathways in its non-ETS sectors.

\section{Materials and Methods}

\subsection{Methodology}

This section offers a general description of the methodology applied. A full description of the model and its equations is provided in the Appendix A. In the context of reducing emissions of greenhouse gases, a social planner designs an appropriate mix of GHG mitigation policies and measures, which comprises a set of options described by (a) their emissions abatement cost, (b) their emissions abatement potential, and (c) the implementation speed of each measure. The aim is to meet the emission reduction objective in the target year, at least cost to society. The objective function that needs to be minimized is the total present cost of abatement. The model runs for the period 2021-2050 with a time step of one year.

Each abatement measure has an abatement cost expressed in Euros per tonne of $\mathrm{CO}_{2}$-equivalent (tn $\mathrm{CO}_{2 \mathrm{e}}$ ) and an attainable abatement potential expressed in avoided annual emissions in tn $\mathrm{CO}_{2 \mathrm{e}}$ per year. The optimization problem to be solved is the selection of the amount of abatement to be implemented by measure each year, in order to achieve future emission reduction targets at the minimum cost. For each measure, the emissions abatement cost is given based on prior calculations or literature data.

For each measure there is a maximum abatement potential, expressed in avoided emissions in tn $\mathrm{CO}_{2 \mathrm{e}}$. The cumulative abatement of each measure up to 2050 cannot exceed the full abatement potential of that measureEach abatement measure takes time to realize. For example, energy renovations of buildings cannot happen overnight for the whole building stock because of constraints in financial, human and raw material resources; deployment of electric vehicles requires adequate infrastructure investments, changes in the regulatory environment and adaptation of consumer habits. Therefore, irrespective of the full abatement potential, each measure has a maximum implementation speed, expressed in maximum annual abatement that can be achieved per year [ $\operatorname{tn} \mathrm{CO}_{2 \mathrm{e}} / \mathrm{y} / \mathrm{y}$ ]. This has been introduced by Vogt-Schilb and Hallegatte [3]. A new feature in our model is that this speed can change over time, to reflect inertia in the uptake of low-carbon technologies and in consumer behaviour. For example, adoption of electric vehicles or shift of passenger mobility to public transport modes will most probably start at low speed, based on some pioneering initiatives (e.g., the first charging stations that will serve the first few purchasers of electric cars; or the first municipalities to use smart public transit and other facilities to attract car drivers to shift to public transport; etc.).

It will take years for such measures to diffuse in the economy to a sufficient extent; and the more one delays implementation of these measures the longer it will take for a measure to achieve its maximum implementation speed. Therefore, we assume annual values of speed to depend on the cumulative amount of abatement that has already been deployed up to that year.

The model computes the least-cost implementation schedule of the various mitigation measures for achieving the desirable emissions targets. The emissions objectives for given points in time (2030 and 2050) that need to be satisfied, are set with corresponding emission constraints. Thus the optimization problem becomes to select annual abatement by measure in order to minimize discounted social costs, subject to the constraints mentioned above.

\subsection{Data and Assumptions on Policies and Measures}

A detailed list of GHG emission abatement measures, along with the associated investment, maintenance and fuel costs and the emission abatement potential of each one, is provided by Sotiriou et al. [9]. In summary, the following measures were considered for reducing GHG emissions from non-ETS sectors:

- In residential buildings, emission reductions are mainly due to the implementation of specific energy renovations in buildings that were constructed before 2008 and complied with low or no 
energy performance requirements. Such measures comprise: renovation of the building so that it becomes a near-Zero Energy Building (nZEB), also called 'deep renovation'; roof insulation; wall insulation; insulation of pilotis (columns or similar structural elements that support a building above ground); and investment in modern very energy efficient heat pumps which replace older space heating and space cooling systems.

- In buildings of the tertiary sector, energy renovations similar to those of residential buildings were considered. An additional measure is the use of CHP (combined heat and power generation or cogeneration) in hotels and hospitals, which have considerable hot water requirements.

- In non-ETS industrial sectors, the two main measures considered were to replace fuel oil fired burners with modern ones, thereby attaining an efficiency of over $90 \%$; and industrial cogeneration.

- Infrastructure investments for promoting public transport that will reduce the use of passenger cars correspondingly.

- Use of alternative fuels in road transport: promoting the purchase of (a) all-electric passenger cars and (b) trucks powered with compressed natural gas (CNG).

- Promotion of anaerobic digestion in the waste sector in order to reduce emissions of methane; this applies to both animal waste (i.e., manure management) and municipal solid waste, and can be realized by exploiting the full biogas production capacity of existing plants that process animal waste, and through investments in new anaerobic digesters.

Table 1 presents the initial abatement costs for each policy and measure considered. Details on the methodology and the assumptions underlying these figures are provided by [9]. It should be noted that the analysis is performed from the perspective of a social planner who attempts to maximize social welfare, i.e., from a public policy viewpoint. Therefore, costs are net of taxes and duties and a real social discount rate of $4 \%$ is used to determine the present value of future cash flows. Measures displaying a negative abatement cost seem to be beneficial to the country from a public policy perspective, even if they may require economic incentives to enable their uptake by private investors.

While the third column of Table 1 shows the estimated monetary costs, the last column adds to these the associated external costs of each measure. This is the net effect of the damage costs due to additional emissions of pollutants and/or greenhouse gases because of the introduction of an abatement measure, minus the damage costs that will be avoided thanks to reduced emissions of these measures. For example, the introduction of electric cars saves emissions from conventional fossil fuel powered cars but leads to additional emissions from the thermal power plants generating the corresponding amount of electricity to operate these cars. External costs are calculated on the net difference of these emissions.

We have included the external costs of GHG, $\mathrm{NOx}, \mathrm{PM}$ and $\mathrm{SO}_{2}$ emissions. To conduct this assessment, emissions generated and avoided from a specific abatement measure have to be calculated and multiplied by the marginal damage cost, expressed in Euros per tonne of each gas. Emission of air pollutants were calculated on the basis of the methodology included in the European Monitoring and Evaluation Programme (EMEP)/European Environment Agency (EEA) Emissions Inventory Guidebook [10], applying national data on fuel quality and power generation emissions. Details on this calculation are provided by Zachariadis and Hadjikyriakou [11].

As far as external costs are concerned, for GHG emissions we used the assessment of marginal damage costs made by the U.S. Environmental Protection Agency [12]. These costs are intended to reflect all long-term damages related to climate change (e.g., on agricultural production, human health, ecosystems etc.), and are called 'social cost of carbon'. Zachariadis and Hadjikiyriakou [11] used these data after converting them to real Euros per tonne of $\mathrm{CO}_{2}$. For assessing the cost of NOx, PM and $\mathrm{SO}_{2}$ emissions, calculations of the European studies were used-results from the CASES project [13] for emissions from power plants, and from Ricardo-AEA [14] for road transport emissions. The total cost of each pollutant is the sum of the effect of damages on human health, crops, materials and biodiversity. All values were transformed to constant Euros per tonne of pollutant, and are shown in Table 2. Damage costs increase over the years because the disposable income is projected to continue 
increasing in the next decades; this raises the corresponding willingness of populations to pay for reducing pollutant-induced risks. In the case of GHG emissions, an additional reason for rising damage costs over the years is associated with the accumulation of GHG in the atmosphere, so that a tonne of GHG emitted in the future is expected to cause more damages than a tonne of GHG emitted today.

Comparing the two last columns of Table 1, it is evident that inclusion of external costs reduces the cost of most mitigation measures. The difference in costs when accounting for externalities is particularly noteworthy in the three transport-related measures, whose abatement cost is initially positive and turns to negative when pollution damages are accounted for; this is obviously due to the strong benefits thanks to avoided emissions of air pollutants especially in urban areas. Similarly, abatement costs of cogeneration measures and anaerobic digestion of waste are strongly reduced when air pollution costs are taken in consideration, thanks to the avoided emissions of air pollutants because of reduced needs to produce electricity from conventional thermal power plants. On the other side, there are few measures whose abatement costs increase when pollutant emissions costs are included; this is the case with heat pump installation, as this is expected to increase thermal power generation and hence the associated pollutant emissions. It has to be reminded that most power generation in Cyprus comes from power plants burning fuel oil and gas oil, which are scheduled to be gradually converted to natural gas fired plants.

Table 1. Abatement costs of policies and measures considered.

\begin{tabular}{|c|c|c|c|}
\hline Measure & Sector & $\begin{array}{l}\text { Abatement Cost } \\
{\left[\epsilon^{\prime} 2015 / \operatorname{tn} \mathrm{CO}_{2 \mathrm{e}}\right]}\end{array}$ & $\begin{array}{c}\text { Abatement Cost with } \\
\text { Externalities }\left[\epsilon^{\prime} 2015 / \text { tn } \mathrm{CO}_{2 \mathrm{e}}\right]\end{array}$ \\
\hline Roof Insulation, multi-family building pre-2008 & Residential & -354.8 & -414.8 \\
\hline Heat Pumps, multi-family building pre-2008 & Residential & -348.0 & -315.0 \\
\hline Heat Pumps, single-family building pre-2008 & Residential & -533.6 & -500.7 \\
\hline Full Renovation, multi-family building pre-2008 & Residential & 1967.1 & 1907.1 \\
\hline Pilotis Insulation, multi-family building pre-2008 & Residential & 59.4 & -37.8 \\
\hline Wall Insulation, multi-family building pre-2008 & Residential & 2528.4 & 2468.4 \\
\hline Wall Insulation, single-family building pre-2008 & Residential & 7904.8 & 7837.4 \\
\hline Cogeneration $(\mathrm{CHP})$ in the services sector & Services & -389.2 & -593.8 \\
\hline Cogeneration $(\mathrm{CHP})$ in industry & Industry & -334.9 & -533.1 \\
\hline Replacement of industrial burners & Industry & -251.1 & -449.3 \\
\hline Introduction of electric cars & Transport & 59.1 & -22.1 \\
\hline Promotion of public transport & Transport & 69.0 & -8.2 \\
\hline Introduction of CNG-powered trucks & Transport & 95.2 & -645.5 \\
\hline Anaerobic digestion for animal \& municipal waste & Agriculture & 3.9 & -40.6 \\
\hline
\end{tabular}

Table 2. Costs of GHG and air pollutant emissions up to 2040, in $€^{\prime 2015 / t n . ~}$

\begin{tabular}{cccccc}
\hline Year & $\mathbf{2 0 2 0}$ & $\mathbf{2 0 2 5}$ & $\mathbf{2 0 3 0}$ & $\mathbf{2 0 3 5}$ & $\mathbf{2 0 4 0}$ \\
\hline $\mathrm{GHG}$ & 35.4 & 38.6 & 42.7 & 46.0 & 50.1 \\
$\mathrm{NO}$ & 7624 & 8286 & 9006 & 9392 & 9793 \\
$\mathrm{PM}$ & 135,000 & 137,500 & 140,000 & 142,500 & 145,000 \\
$\mathrm{SO}_{2}$ & 13,923 & 15,121 & 16,425 & 17,122 & 17,849 \\
\hline
\end{tabular}

As described in the previous section, the model also requires information about variable $s_{j, t}$, the speed of implementation of each measure, which was not included in Sotiriou et al. [9]. Assumptions about this speed differ, based on the following considerations:

- In the specific case of energy renovations in pre-2008 buildings, the speed of implementation up to 2030 was based on technical and financial constraints—see Tables A2 and A5 of Sotiriou et al. [9]. From 2031 onwards it was assumed that no further energy renovations will take place because it would not be realistic to perform such renovations in buildings over 25 years old.

- For emission abatement measures that require modest public or private investments, we assumed that $s$ remains essentially constant or rises slightly over the years of the period 2021-2050; this is the case of industrial and commercial cogeneration and the replacement of industrial burners. 
The annual speed depends on the technical capacity available in the country for proceeding with such investments, based on information collected by industrial experts.

- Abatement measures that require substantial investments in infrastructure were assumed to be implemented with relatively low initial speeds, which gradually increase over the years, depending on the cumulative abatement achieved up to a specific year. This is the case with anaerobic digestion of animal and municipal waste, which requires both the construction of additional digesters and sufficient facilities to transport and store waste from different locations. This is also the case with promotion of public transport, electric cars and CNG trucks because each one of these measures needs large investments in relevant infrastructure-smart bus systems and bus lanes; sufficient electric charging stations for cars; and adequate CNG refuelling stations. The existence of such infrastructure is expected to gradually enable behavioural changes that will induce increased use of public transport and steadily rising purchases of electric cars and CNG trucks.

Table 3 provides an overview of these assumptions.

Table 3. Speed of implementation of each emission abatement policy and measure considered.

\begin{tabular}{|c|c|c|c|}
\hline Measures & Sector & $\begin{array}{c}\text { Initial } \\
\text { Implementation } \\
\text { Speed }\left[\operatorname{tn} \mathrm{CO}_{2 \mathrm{e}} / \mathrm{y} / \mathrm{y}\right]\end{array}$ & Comments \\
\hline $\begin{array}{l}\text { Roof Insulation, multi-family } \\
\text { building pre-2008 }\end{array}$ & Residential & 1.38 & $\begin{array}{l}1400 \text { buildings renovated each year in } \\
2021-2030 \text {, no renovations post-2030 }\end{array}$ \\
\hline $\begin{array}{l}\text { Heat Pumps, multi-family } \\
\text { building pre-2008 }\end{array}$ & Residential & 1.14 & $\begin{array}{l}450 \text { buildings renovated each year in } \\
2021-2030 \text {, no renovations post- } 2030\end{array}$ \\
\hline $\begin{array}{l}\text { Heat Pumps, single-family } \\
\text { building pre-2008 }\end{array}$ & Residential & 1.51 & $\begin{array}{l}750 \text { buildings renovated each year in } \\
2021-2030 \text {, no renovations post- } 2030\end{array}$ \\
\hline $\begin{array}{l}\text { Full Renovation, multi-family } \\
\text { building pre-2008 }\end{array}$ & Residential & 0.42 & $\begin{array}{l}150 \text { buildings renovated each year in } \\
2021-2030 \text {, no renovations post-2030 }\end{array}$ \\
\hline $\begin{array}{l}\text { Pilotis Insulation, multi-family } \\
\text { building pre-2008 }\end{array}$ & Residential & 0.09 & $\begin{array}{l}90 \text { buildings renovated each year in } \\
2021-2030 \text {, no renovations post-2030 }\end{array}$ \\
\hline $\begin{array}{l}\text { Wall Insulation, multi-family } \\
\text { building pre-2008 }\end{array}$ & Residential & 0.09 & $\begin{array}{l}180 \text { buildings renovated each year in } \\
2021-2030, \text { no renovations post-2030 }\end{array}$ \\
\hline $\begin{array}{l}\text { Wall Insulation, single-family } \\
\text { building pre-2008 }\end{array}$ & Residential & 0.09 & $\begin{array}{l}750 \text { buildings renovated each year in } \\
2021-2030 \text {, no renovations post- } 2030\end{array}$ \\
\hline $\begin{array}{l}\text { Cogeneration }(\mathrm{CHP}) \text { in the } \\
\text { services sector }\end{array}$ & Services & 3.34 & $\begin{array}{l}\text { Approximately } 200 \mathrm{CHP} \text { units installed in } \\
\text { total, mainly in hotels and hospitals; slightly } \\
\text { increasing implementation speed up to } 2050\end{array}$ \\
\hline Cogeneration $(\mathrm{CHP})$ in industry & Industry & 3.34 & $\begin{array}{l}\text { Approximately } 200 \mathrm{CHP} \text { units installed in } \\
\text { total, slightly increasing implementation } \\
\text { speed up to } 2050\end{array}$ \\
\hline $\begin{array}{l}\text { Replacement of industrial } \\
\text { burners }\end{array}$ & Industry & 0.07 & $\begin{array}{l}\text { Burners of total thermal capacity of } \\
12,000 \mathrm{~kW} \text { to be replaced; constant } \\
\text { implementation speed up to } 2050\end{array}$ \\
\hline Introduction of electric cars & Transport & 2.08 & $\begin{array}{l}\left(1000+1000^{*} \mathrm{t}\right) \text { new electric cars sold each } \\
\text { year } \mathrm{t} \text { of period } 2021-2040 \text {, then constant } \\
\text { speed up to } 2050 ; \text { post-2040 all newly } \\
\text { registered cars are electric }\end{array}$ \\
\hline Promotion of public transport & Transport & 2.79 & $\begin{array}{l}\text { Total number of passenger kilometres } \\
\text { (pkm) shifted from private cars to buses: } \\
7 \% \text { up to } 2030 \text { with constant speed, and } \\
\text { then } 30 \% \text { up to } 2050 \text { with constant speed }\end{array}$ \\
\hline $\begin{array}{c}\text { Introduction of CNG-powered } \\
\text { trucks }\end{array}$ & Transport & 0.50 & $\begin{array}{l}\text { New trucks sold up to } 2050 \text { use Compressed } \\
\text { Natural Gas as a fuel, gradual increase of } \\
\text { implementation speed through the years }\end{array}$ \\
\hline $\begin{array}{l}\text { Anaerobic digestion for animal } \\
\qquad \& \text { municipal waste }\end{array}$ & Agriculture & 1.55 & $\begin{array}{l}\text { Extra amount of waste per year to be } \\
\text { directed to anaerobic digestion, increase } \\
\text { of speed through the years }\end{array}$ \\
\hline
\end{tabular}




\section{Simulation Results}

We perform two types of optimization runs with our model. One is a joint optimization for both target years 2030 and 2050. In other words, the model is forced to solve the dynamic abatement problem satisfying both emission constraints. This enables policymakers to design a decarbonization policy that meets the 2030 objective as well as the 2050 commitment. We call this 'joint optimization'. In the second type of run, which we call 'split optimization', the model is initially solved for the period 2021-2030, with the 2030 emissions target as the only constraint; then at a second stage, the model solves for annual abatement in the period 2031-2050, taking into account the solution of 2021-2030 and having as a constraint the 2050 emissions target.

Based on initial trials of the model with the data that have been included and the assumptions explained in Section 2, we arrived at a maximum emissions abatement value of $1602 \mathrm{tn} \mathrm{CO}_{2 \mathrm{e}}$ in the year 2050; this corresponds to an approximately $60 \%$ reduction in non-ETS GHG emissions of a base year. Keeping the 2050 constraint fixed at this value, we then employed the two types of runs for different emission constraints for the year 2030. The 2030 abatement constraints were 100, 150, 200 and $280 \mathrm{tn}$ $\mathrm{CO}_{2 \mathrm{e}}$, respectively, which correspond to increasing levels of ambition for emission reduction in year 2030 .

Figure 1 presents the evolution of GHG emissions up to 2050 according to the two types of runs, for the case of $100 \mathrm{tn} \mathrm{CO}_{2 \mathrm{e}}$ abatement in 2030. In order to abstract from specific numbers (which in this study are relevant for Cyprus only) and highlight the main policy message that is relevant for all countries, we call this 2030 abatement level as 'unambitious', and express all values as a fraction of the base year emissions. It is evident that, if the 2030 objective is unambitious, the decarbonization target of 2050 can only be met if one solves the joint optimization problem. The latter strategy may over achieve the 2030 objective-joint optimization leads to lower emissions in 2030 than what is required by the constraint.

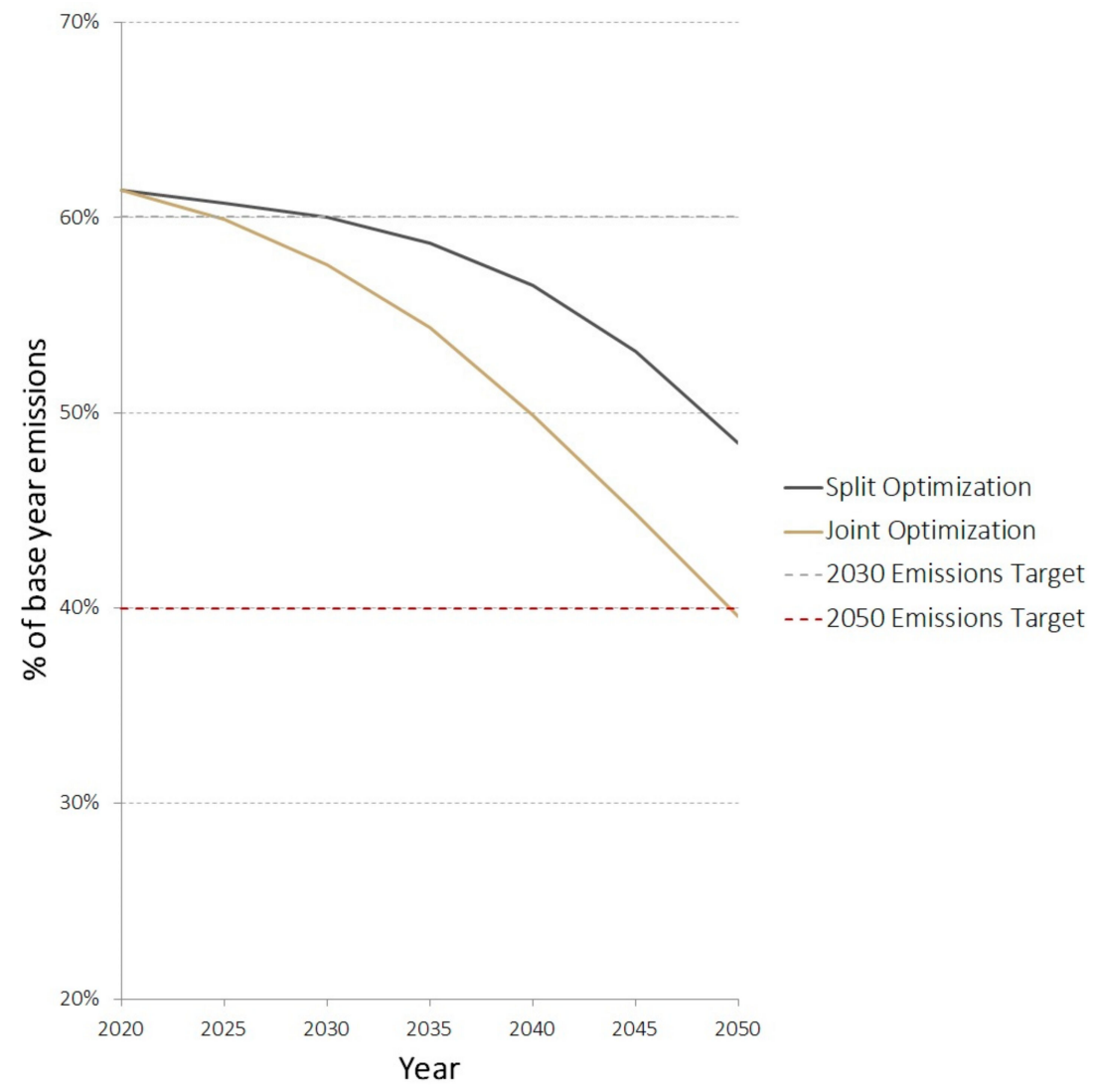

Figure 1. Evolution of non-ETS GHG emissions with an unambitious abatement target for 2030, depending on whether policymakers optimize jointly for years 2030 and 2050 or at two stages, i.e., one optimization in 2020 for the 2030 target and one in 2030 for the 2050 target. 
Conversely, if a policymaker designs a strategy in 2020 keeping in mind only the 2030 target, deep decarbonization of year 2050 cannot be achieved. The reason for this failure is that abatement measures with high potential which take time to mature, such as electric cars or public transport, cannot deliver their full potential until 2050 if deployed after 2030; early deployment of seemingly expensive measures is necessary in order to achieve serious decarbonization in 2050. This is highlighted in Figure 2, which compares cumulative abatement up to 2050 for the two approaches. In the absence of an ambitious 2030 target, the split optimization approach achieves much less abatement in 2050 because measures whose implementation does not start early enough (electric cars, CNG trucks, public transport, anaerobic digesters) reach about half of their full potential in 2050. Figure 3 zooms specifically in year 2030 and presents the same result with Figure 2, highlighting both the different level of cumulative abatement and the different mix of policies that a policymaker chooses, depending on whether her focus is on attaining both 2030 and 2050 targets (joint optimization) or the 2030 target only (split optimization). It has to be stressed that these values refer to non-ETS emission reduction objectives only; attaining a 2030 or 2050 target in non-ETS sectors does not imply anything about meeting the objectives of ETS sectors, which is also a demanding task [15].

For comparison, Figure 4 shows the corresponding evolution for the case of $200 \mathrm{tn} \mathrm{CO}_{2 \mathrm{e}}$ abatement in 2030. This can be considered a clearly more ambitious target. Here again, the joint optimization is the only one achieving the 2050 objective, and to do this it is necessary to overachieve the 2030 target. However, the emissions gap in 2050 is much smaller than in Figure 1. Because of the need to attain the ambitious target of 2030, many high-potential abatement measures start being deployed before 2030 . As a result, it makes little difference whether the policymaker designs a strategy keeping both targets in mind already in 2020, or develops the strategy in two stages.

Figure 5 highlights this message. With an even more ambitious target for 2030, both optimization strategies lead to the same result, and the 2050 emissions difference between the two approaches becomes zero. Conversely, the less ambitious the 2030 strategy is the more important it is to design a strategy already in 2020 keeping in mind the 2050 target as well. Otherwise, ignoring the 2050 target in 2020 leads to an under achievement of the 2050 objective by more than $35 \%$.

Apart from differences in aggregate emission abatement, the two optimization approaches lead to different aggregate costs. This is obvious because split optimization in most cases leads to lower total abatement, and therefore to lower total investments in the corresponding abatement measures. However, as shown in Figure 6, this is not the socially optimal approach. An unambitious abatement target for 2030 (the rightmost brown column) leads to $8 \%$ lower discounted aggregate costs, but if one takes into account external costs of emissions of GHG and air pollutants $\mathrm{NOx}, \mathrm{PM}$ and $\mathrm{SO}_{2}$, the difference in cost becomes essentially zero. Keeping in mind that other externalities, such as emissions of other pollutants, road congestion and noise have not been accounted for in these calculations, it becomes evident that the full GHG emissions abatement is also the economically preferable solution. This finding is consistent with work presented by the World Bank [16], where the multiple benefits of climate change mitigation were monetized. 


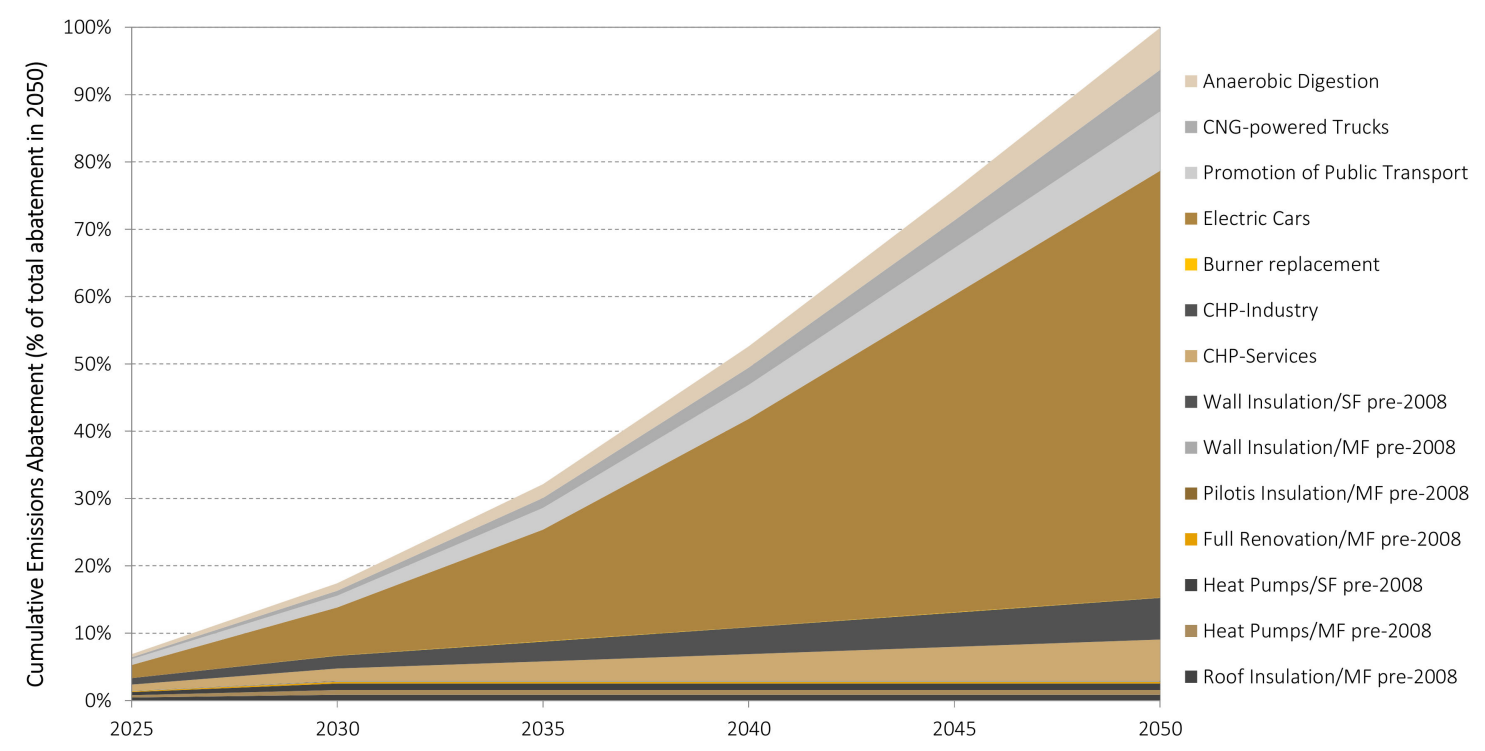

(a)

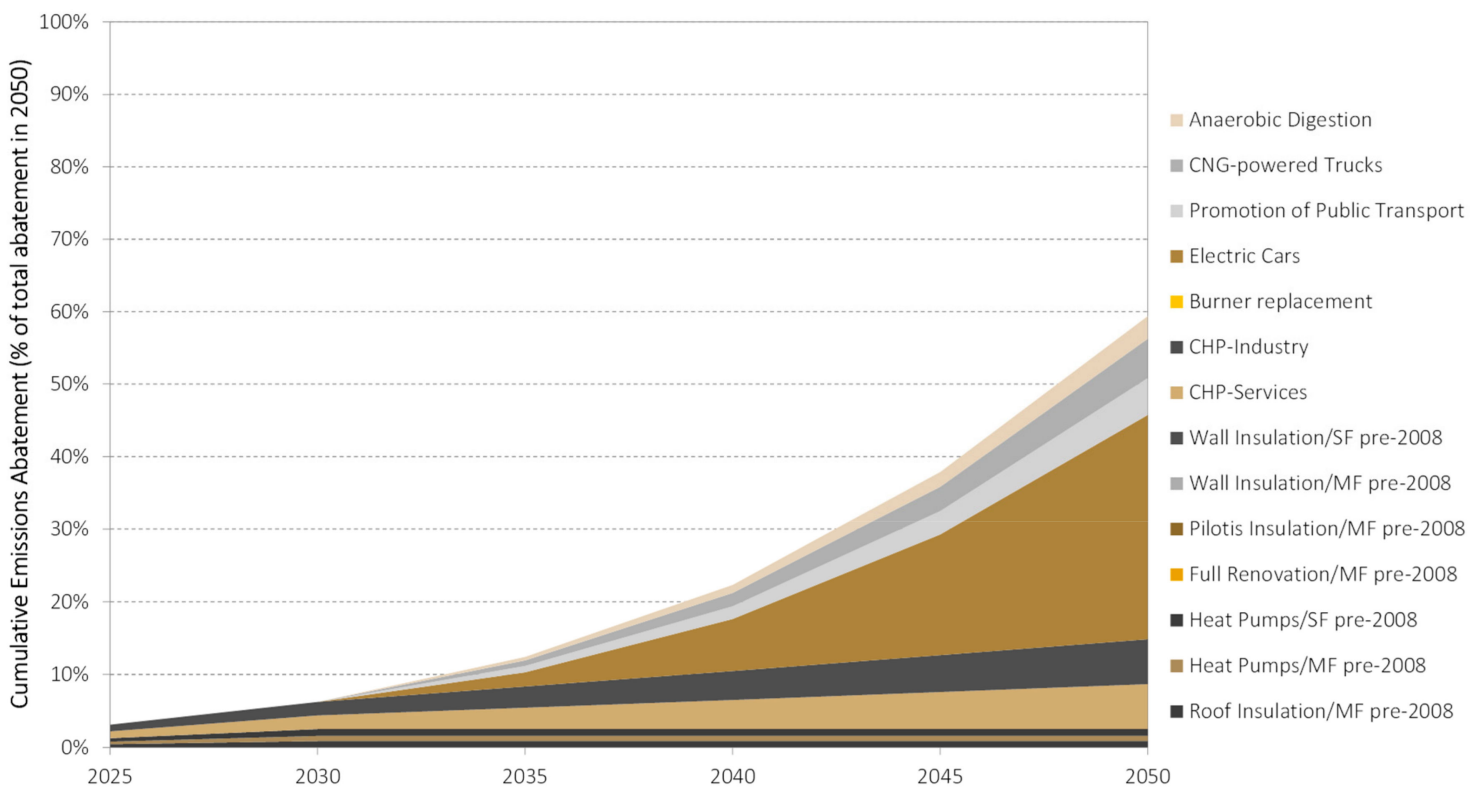

(b)

Figure 2. Emission abatement in non-ETS sectors up to 2050 by type of measure, when the 2030 target is unambitious: (a) Joint optimization which reaches the full abatement target in 2050, (b) Split two-stage optimization, which falls short of the 2050 target because measures that take time to mature develop less than their full potential up to 2050. 


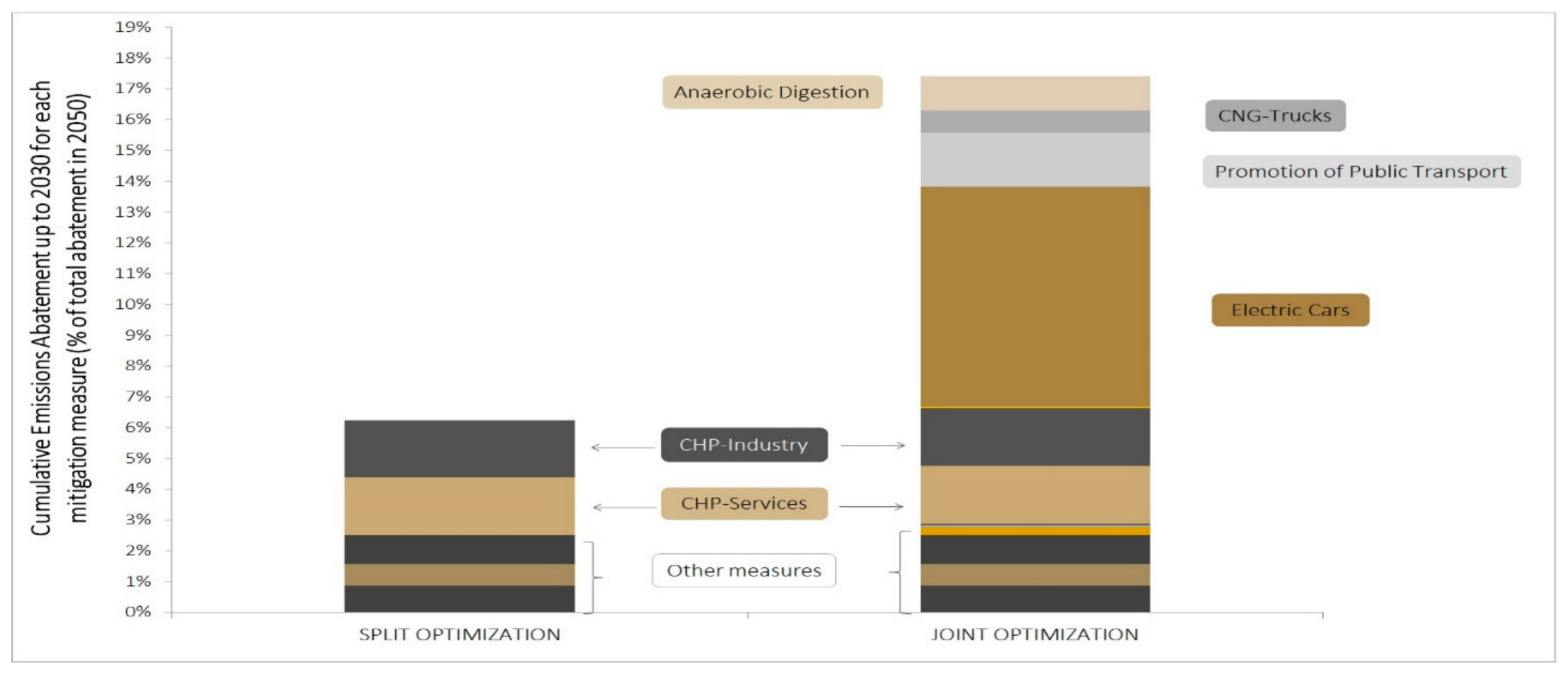

Figure 3. Non-ETS emission abatement achieved in year 2030 for an unambitious 2030 target. Left column: optimization keeping in mind the 2030 objective only. Right column: joint optimization which has been designed to attain the 2030 target and also reach the full abatement target in 2050.

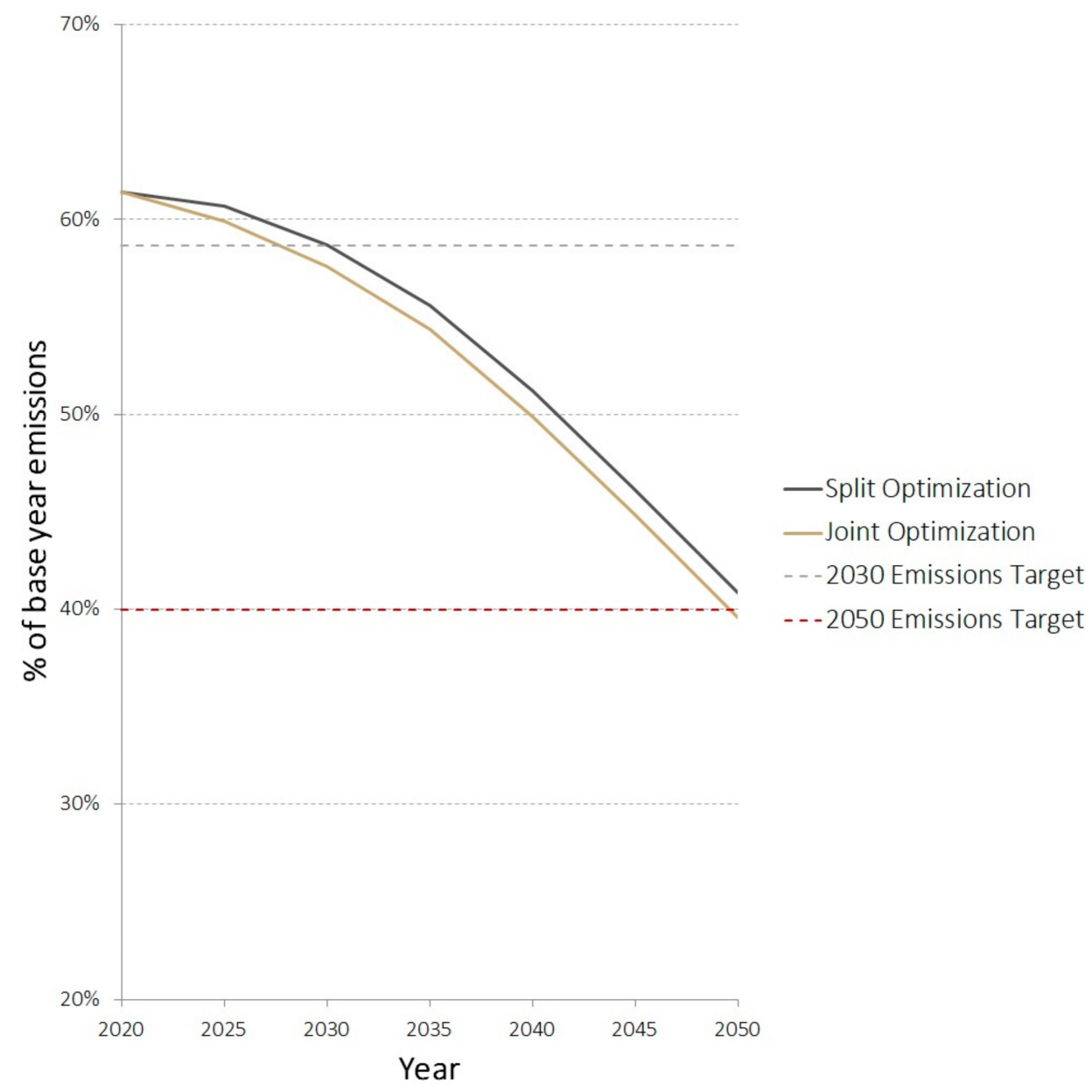

Figure 4. Evolution of non-ETS GHG emissions with an ambitious abatement target for 2030. 
Only An Ambitious 2030 Target Leads to Fulfilment of the $\mathbf{2 0 5 0}$

Target

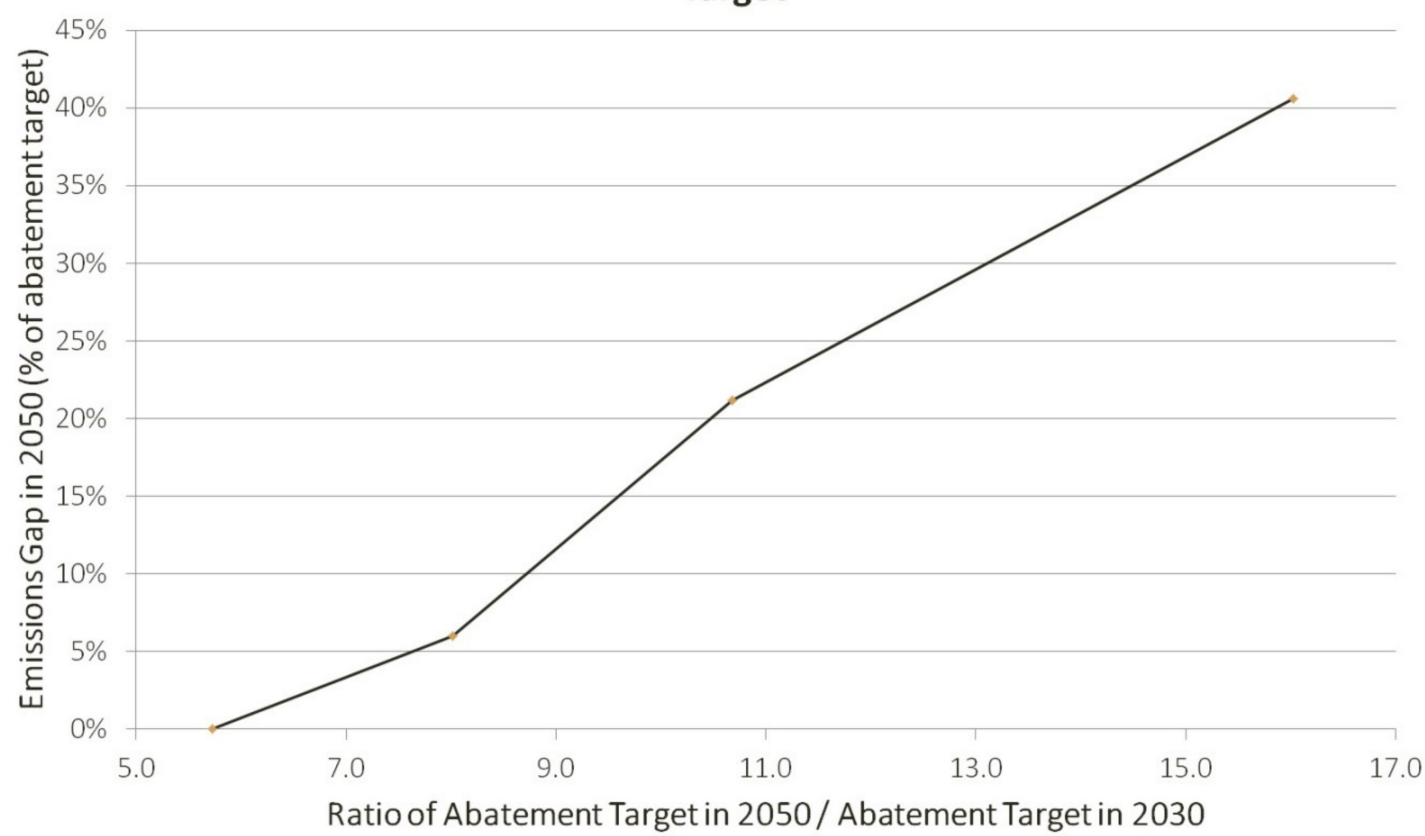

Figure 5. Emissions gap in 2050, depending on the ambition level of emissions abatement in 2030. The gap is defined as the difference between the desired abatement in 2050 and the abatement realized when the optimal policy is determined in two stages. The lower the ratio on the horizontal axis the more ambitious the 2030 abatement target.

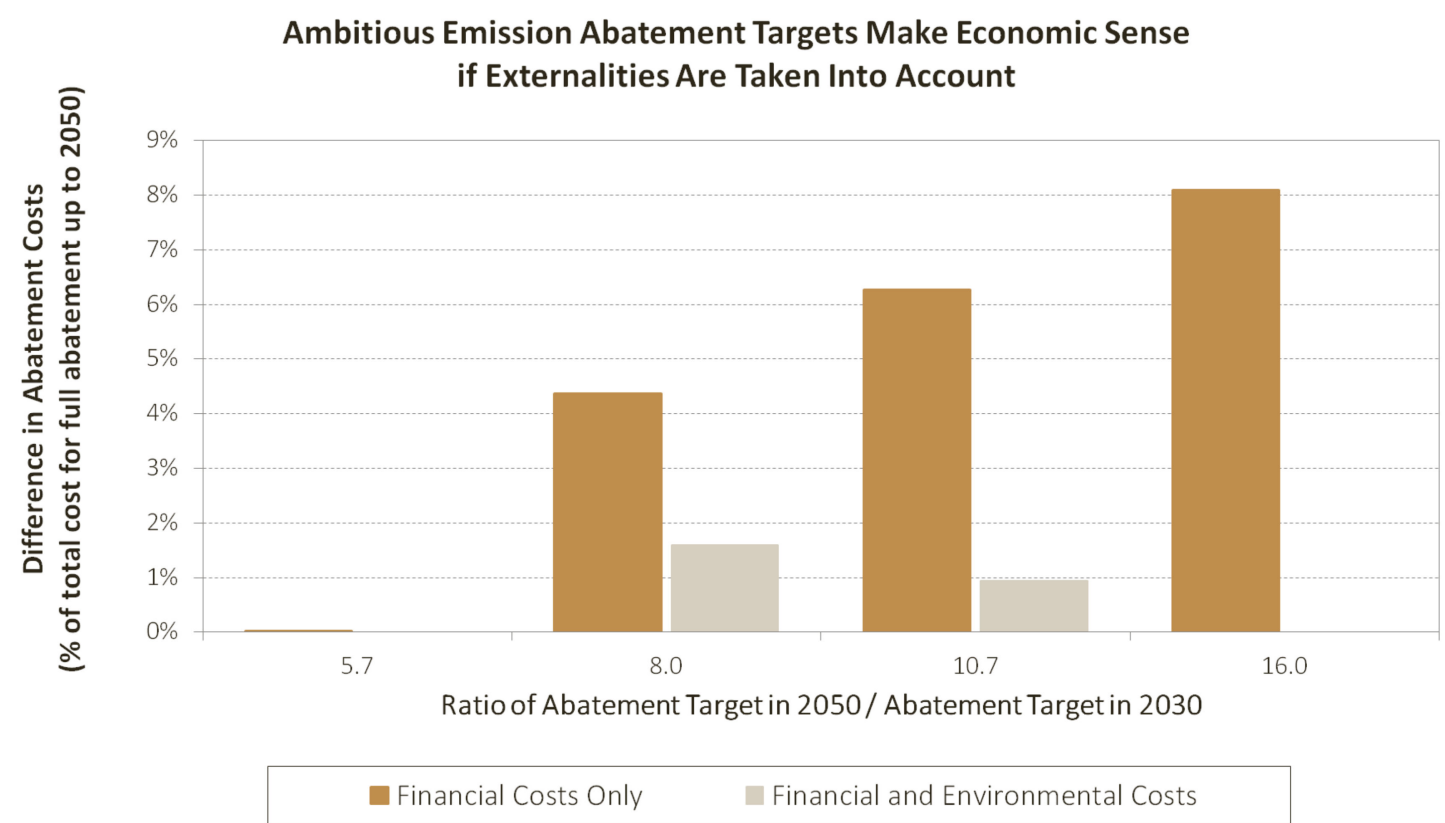

Figure 6. Difference in total discounted abatement costs up to 2050, depending on the ambition level of emissions abatement in 2030. The lower the ratio on the horizontal axis the more ambitious the 2030 abatement target. Environmental costs include damages from GHG, NOx, $\mathrm{PM}$ and $\mathrm{SO}_{2}$ emissions.

\section{Discussion and Conclusions}

Decarbonization by the mid-21st century requires strong commitment to greenhouse emission abatement measures, but national emission reduction pledges are made for the medium term. Achieving medium term targets without taking into account the long term can lead to a lock-in effect, whereby 
policies to reduce emissions in the medium term bind countries in pathways that cannot lead to strong decarbonization in the longer term. In this paper we attempt to shed light in this issue by combining a theoretical approach with real-world engineering and cost data from the EU Member State of Cyprus. We develop a multi-objective constrained optimization model to examine least-cost GHG emission abatement pathways, taking into account: (a) emission reduction objectives for two years: 2030 and 2050; and (b) the potential speed of implementation of each measure, which expresses technical and behavioural inertia in the deployment of a measure. Our focus is on European countries and non-ETS sectors, i.e., economic sectors that are not subject to the EU Emissions Trading System. Therefore we abstract from the specific emission calculations of that particular country and express costs and emissions in relative terms. We also take into account environmental side-benefits of GHG emission abatement, by accounting for measure-specific external costs from the emissions of air pollutants.

Our simulations offer evidence that, if the 2030 objective is unambitious, the decarbonization target of 2050 can only be met if a policymaker-already in 2020-decides jointly on the optimal pathway for meeting both 2030 and 2050 objectives. Conversely, if a policymaker designs a strategy in 2020 keeping in mind only the 2030 target, deep decarbonization of year 2050 cannot be achieved. The reason is that abatement measures with high potential which take time to mature, such as electric cars or promotion of public transport, cannot deliver their full potential until 2050 if deployed after 2030; early deployment of seemingly expensive measures is necessary in order to achieve serious decarbonization in 2050. This is in line with findings from other national case studies mentioned in Vogt-Schilb and Hallegatte [17] and recommendations from international organizations [18]. Road and freight transport as well as waste management are the sectors which are particularly vulnerable to unambitious 2030 objectives, because deployment of new vehicle technologies and anaerobic digestion/biogas plants takes time to materialize.

We also find that an unambitious abatement target for 2030 leads to lower discounted aggregate costs up to 2050; however, the cost difference becomes negligible if one takes into account external costs of emissions of GHG and air pollutants $\mathrm{NOx}, \mathrm{PM}$ and $\mathrm{SO}_{2}$. Keeping in mind that other externalities, such as emissions of other pollutants, road congestion and noise have not been accounted for in these calculations, it becomes evident that the full GHG emissions abatement is also the economically preferable solution, as also highlighted by the World Bank [16].

As the Paris Agreement [1] refers to "carbon budgets" that are compatible with a global warming of a certain temperature (e.g., $1.5^{\circ} \mathrm{C}$ or $2{ }^{\circ} \mathrm{C}$ ), it is important to note that our analysis takes as granted the EU policy that was first decided in 2014 (as regards 2030 objectives) and has been recently extended to pledges for climate neutrality [2]. As demonstrated e.g., by Perissi et al. [19], the trajectories for achieving the 2030 and 2050 emission goals, which we take for granted here, are not necessarily compatible with the global carbon budget that underlies the Paris Agreement. To improve this analysis, country-specific optimal emission reduction paths need to be developed-which is an interesting avenue of future research.

In terms of governance, policy experts have found that the current EU energy and climate policies are generally effective, and there are good prospects that the 2030 targets will be achieved [20,21]—although the European Environment Agency's assessment is less optimistic in this regard [8]. Our paper does not evaluate these aspects, but assesses implicitly how adequate the 2030 targets are in order to attain the EU's long-term decarbonization objective. As regards the latter question, although the analysis is not explicitly based on data from all EU member states and hence its general conclusions should be treated with caution, our finding is that more ambitious EU-wide targets have to be set by 2030 in order for Europe to stay on track to deliver deep decarbonization by 2050.

Author Contributions: Conceptualization, T.Z.; methodology, C.S. and T.Z..; software, C.S.; writing-original draft preparation, review and editing, C.S. and T.Z.

Funding: This research received no external funding.

Conflicts of Interest: The authors declare no conflict of interest. 


\section{Appendix A}

\section{Detailed Methodology}

Within the broader policy context of reducing emissions of greenhouse gases, a social planner is required to design an appropriate mix of GHG mitigation policies and measures, which comprises a set of options described by: (a) their emissions abatement cost, (b) their emissions abatement potential, and (c) the implementation speed of each measure.

The aim is to meet the emission reduction objective in the target year, at least cost to society. The objective function that needs to be minimized, i.e., the total present cost of abatement $T C$, is the following:

$$
T C=\sum_{j} \sum_{t} \frac{T C_{j, t}}{(1+r)^{t}}
$$

There are $N$ abatement options, indexed by $j$. The model runs for the period 2021-2050 with a time step of one year, $t$ :

$$
T C_{j, t}=A C_{j, t^{*}} \sum_{i} \frac{a_{j, t}}{(1+r)^{i}}
$$

Each abatement measure $j$ has an abatement cost $A C$ expressed in Euros per tonne of $\mathrm{CO}_{2}$-equivalent (tn $\mathrm{CO}_{2 \mathrm{e}}$ ) and an attainable abatement potential $\alpha$ expressed in avoided annual emissions in tn $\mathrm{CO}_{2 \mathrm{e}}$ per year. $\alpha_{j, t}$ are the decision variables. The optimization problem to be solved is the selection of the amount of abatement to be implemented by measure each year, in order to achieve future emission reduction targets at the minimum cost.

For each measure, the emissions abatement cost $A C$ is given based on prior calculations or literature data. $A C$ is equal to:

$$
A C_{j, t}=\frac{\sum_{i}\left[\frac{I C_{j, t}+M C_{j, t}+F C_{j, t}}{[1+r]^{i}}\right]}{\sum_{i} \frac{\gamma_{j, t}}{(1+r)^{i}}}
$$

where IC, MC and FC denote annual investment, maintenance and fuel costs respectively, and $\gamma$ represents the abatement achieved through the implementation of a specific amount of each measure. All values are discounted at rate $r$ over the measure's lifetime $i$.

For each measure there is a maximum abatement potential $A$, that is expressed in avoided emissions in tn $\mathrm{CO}_{2 \mathrm{e}}$. The cumulative abatement of each measure up to 2050 cannot exceed the full abatement potential $A$ of that measure:

$$
\sum_{t} a_{j, t} \leq A_{j}
$$

Each abatement measure takes time to realize. For example, energy renovations of buildings cannot happen overnight for the whole building stock because of constraints in financial, human and raw material resources; deployment of electric vehicles requires adequate infrastructure investments, changes in the regulatory environment and adaptation of consumer habits. Therefore, irrespective of the full abatement potential $A$, each measure has a maximum implementation speed $s$, expressed in maximum annual abatement that can be achieved per year $\left[\operatorname{tn} \mathrm{CO}_{2 \mathrm{e}} / \mathrm{y} / \mathrm{y}\right]$. This has been introduced by Vogt-Schilb and Hallegatte [3]:

$$
a_{j, t} \leq s_{j, t}
$$

A new feature in our model is that $s$ can change over time, to reflect inertia in the uptake of low-carbon technologies and in consumer behaviour. For example, adoption of electric vehicles or shift of passenger mobility to public transport modes will most probably start at low speed, based on some pioneering initiatives (e.g., the first charging stations that will serve the first few purchasers of electric 
cars; or the first municipalities to use smart public transit and other facilities to attract car drivers to shift to public transport; etc.).

It will take years for such measures to diffuse in the economy to a sufficient extent; and the more one delays implementation of these measures the longer it will take for a measure to achieve its maximum implementation speed. Therefore, we assume annual values of $s$ to depend on the cumulative amount of abatement that has already been deployed up to that year:

$$
s_{j, t}=f\left(\sum_{i=1}^{t} a_{j, t}\right)
$$

Finally abatement has to be non-negative:

$$
a_{j, t} \geq 0
$$

The model computes the least-cost implementation schedule of the various mitigation measures for achieving the desirable emissions targets. The emissions objectives for given points in time $m$ (2030 and 2050) that need to be satisfied, are set with the following emission constraint:

$$
\sum_{j} \sum_{t=1}^{m} a_{j, t} \geq a_{m}^{\text {objective }}
$$

Emissions $E$ at time $t$, expressed in th $\mathrm{CO}_{2 \mathrm{e}}$, are calculated from the cumulative baseline emissions $E_{\text {baseline }}$ and the cumulative emissions abatement achieved through the implementation of the available mitigation measures:

$$
E_{t}=E_{\text {baseline }, t}-\sum_{j} \sum_{t} a_{j, t}
$$

Thus the optimization problem becomes to select annual abatement by measure $\left(a_{j, t}\right)$ in order to minimize discounted social costs in line with Equation (A1), subject to the constraints shown in Equations (A4), (A5), (A7) and (A8).

\section{References}

1. EUNFCC. Report of the Conference of the Parties on Its Twenty-First Session, Held in Paris from 30 November to 13 December 2015. FCCC/CP/2015/10/Add1. Available online: http:/unfccc.int/files/home/application/pdf/paris_ agreement.pdf (accessed on 16 May 2019).

2. European Commission. A Clean Planet for All-A European Strategic Long-Term Vision for A Prosperous, Modern, Competitive and Climate Neutral Economy; Document COM (2018) 773 final; European Commission: Brussels, Belgium, 2018. Available online: https://ec.europa.eu/clima/policies/strategies/2050_en (accessed on 16 May 2019).

3. Vogt-Schilb, A.; Hallegatte, S. Marginal abatement cost curves and the optimal timing of mitigation measures. Energy Policy 2014, 66, 645-653.

4. Klitkou, A.; Bolwig, S.; Hansen, T.; Wessberg, N. The role of lock-in mechanisms in transition processes: The case of energy for road transport. Environ. Innov. Soc. Transit. 2015, 16, 22-37.

5. Seto, K.C.; Davis, S.J.; Mitchell, R.B.; Stokes, E.C.; Unruh, G.; Ürge-Vorsatz, D. Carbon lock-in: Types, causes, and policy implications. Annu. Rev. Environ. Resour. 2016, 41, 425-452.

6. Waisman, H.; Bataille, C.; Winkler, H.; Winkler, H.; Jotzo, F.; Shukla, P.; Colombier, M. A pathway design framework for national low greenhouse gas emission development strategies. Nat. Clim. Chang. 2019, 9 , 261-268.

7. Vogt-Schilb, A.; Hallegatte, S.; De Gouvello, C. Marginal abatement cost curves and the quality of emission reductions: A case study on Brazil. Clim. Policy 2015, 15, 703-723.

8. EEA. Trends and Projections in Europe 2018-Tracking Progress towards Europe's Climate and Energy Targets; EEA Report No 16/2018; European Environment Agency: Copenhagen, Denmark, 2018. Available online: https://www.eea.europa.eu/publications/trends-and-projections-in-europe-2018 (accessed on 16 May 2019). 
9. Sotiriou, C.; Michopoulos, A.; Zachariadis, T. On the cost-effectiveness of national economy-wide greenhouse gas emissions abatement measures. Energy Policy 2019, 128, 519-529.

10. EEA. EMEP/EEA Emission Inventory Guidebook 2013; Technical report No 12/2013; European Environment Agency: Copenhagen, Denmark, 2013.

11. IWG (Interagency Working Group on Social Cost of Carbon). Technical Support. Document: Technical Update of the Social Cost of Carbon for Regulatory Impact Analysis under Executive Order 12866; United States Government: Washington, DC, USA, 2013. Available online: https://www.google.com/search?q=Technical+Support. +Document $\% 3 \mathrm{~A}+$ Technical+Update+of+the+Social+Cost+of+Carbon+for+Regulatory+Impact+Analysis+ under+Executive+Order+12866\&rlz=1C1GGRV_enDE753DE753\&oq=Technical+Support.+Document $\%$ $3 \mathrm{~A}+$ Technical+Update+of+the+Social+Cost+of+Carbon+for+Regulatory+Impact+Analysis+under+ Executive+Order+12866\&aqs=chrome..69i57.348j0j4\&sourceid=chrome\&ie=UTF-8 (accessed on 16 May 2019).

12. Zachariadis, T.; Hadjikyriakou, C. Social Costs and Benefits of Renewable Electricity Generation in Cyprus; SpringerBriefs in Energy; Springer International Publishing: New York, NY, USA, 2018.

13. FEEM. CASES (Cost Assessment for Sustainable Energy systems)-Final Conference Proceedings and External Costs Database. 2008. Available online: http://www.feem-project.net/cases/downloads_deliverables.php (accessed on 16 May 2019).

14. Ricardo-AEA. Update of the Handbook on External Costs of Transport. Report for the European Commission's Directorate General for Mobility and Transport. 2014. Available online: https:/ec.europa.eu/transport/ themes/sustainable/studies/sustainable_en (accessed on 16 May 2019).

15. ECF (European Climate Foundation). Roadmap 2050-A Practical Guide to a Prosperous, Low-Carbon Europe. 2010. Available online: http://www.roadmap2050.eu/reports (accessed on 16 May 2019).

16. World Bank. Climate-Smart Development; ClimateWorks Foundation: Washington, DC, USA; World Bank Group: Washington, DC, USA, 2014.

17. Vogt-Schilb, A.; Hallegatte, S. Climate policies and nationally determined contributions: Reconciling the needed ambition with the political economy. WIREs Energy Environ. 2017, 6, e256. [CrossRef]

18. OECD/The World Bank/UN Environment. Financing Climate Futures; OECD Publishing: Paris, France, 2018. [CrossRef]

19. Perissi, I.; Falsini, S.; Bardi, U.; Natalini, D.; Green, M.; Jones, A.; Sole, J. Potential european emissions trajectories within the global carbon budget. Sustainability 2018, 10, 4225. [CrossRef]

20. Oberthür, S. Hard or soft governance? The EU's climate and energy policy framework for 2030. Politics Gov. 2019, 7, 17-27.

21. Ringel, M.; Knodt, M. The governance of the European Energy Union: Efficiency, effectiveness and acceptance of the winter package 2016. Energy Policy 2018, 112, 209-220. 